\title{
RF Radiation Behavior of Rare Gas in Plasma State
}

\author{
N. A. Halili ${ }^{1}$, M. T. Ali ${ }^{1}$, I. Pasya ${ }^{1}$, A. N. Dagang ${ }^{2}$, H. Ja'afar $^{1}$, H. M. Zali ${ }^{1}$ \\ ${ }^{1}$ Antenna Research Center (ARC), Microwave Technology Center (MTC), Faculty of Electrical Engineering, \\ Universiti Teknologi MARA (UiTM), Shah Alam, \\ Selangor, Malaysia \\ ${ }^{2}$ School of Ocean Engineering, Universiti Malaysia Terengganu (UMT), Kuala Terengganu, Terengganu, \\ Malaysia
}

\begin{abstract}
This paper analyzed the performance of monopole plasma antenna based on RF charging using different number of turns of coupling sleeve and different gases. The plasma antennas were designed with 3 different gases which are argon, nitrogen and fluorescent with pressure 10 Torr. For argon plasma antenna, different pressure was designed to analyze the performance of plasma antenna with pressure 0.5 Torr, 1 Torr, 5 Torr and 10 Torr. The dimension of discharge tube for argon and nitrogen is $130 \mathrm{~mm}$ length and $10 \mathrm{~mm}$ diameter, while for fluorescent $145 \mathrm{~mm}$ length and $12 \mathrm{~mm}$ diameter. The dimension of commercialize fluorescent were used as benchmark for other plasma antenna. The commercially fluorescent tubes contain mixture of vapour mercury and argon. The plasma antennas were driven by radio frequency $(R F)$ to sufficiently ionize the gas inside the tube to convert them into plasma state. Each antenna with different configuration of type of gas and pressure was tested while varying the number of coils turns. The antenna's capability to operate as transceiver was verified through simulation by using CST Microwave Studio.
\end{abstract}

Keywords: Plasma antenna, RF signal source, argon, nitrogen, fluorescent, pressure; copper coil; number of turns

\section{Introduction}

The utilization of plasma technology in wireless communication has been developed due to its potential and innovativeness. Ionized plasma is a conductor element and functions as an radio frequency (RF) element for transmitting and receiving electromagnetic wave [1]. The ionized plasma has the ability to be turned on and off, reducing its radar cross section and unwanted effects i.e mutual couplings, on the RF network. Furthermore, this ability can also be manipulated to construct a re-configurable antenna system. Therefore, plasma technology is in accordance with current and near future requirements.

Plasma antenna is a type of antenna in which the metal conducting elements of a conventional antenna are replaced by plasma. Plasma antenna works when a contained gas is ionized into plasma state and become electrically conductive so that it responds strongly to magnetic fields and can be used as an antenna when RF is supplied [2] -[3]. For antenna applications, the antenna must be maintained in precise spatial distributions such as filaments, columns, or sheets. The plasma volume can be contained in an enclosure (tube) or suspended in free space [4]. By containing the plasma in a plasma in a glass tube (afterwards termed as plasma column), one could parameterize various elements of the plasma charging setup to properly design an efficient antenna. Rayneret. al. successfully evaluated the relations of several parameters such as the column length, applied RF power and plasma density to specific conventional metal antenna characteristics in [2]. Furthermore, it was also found that the characteristic of a plasma antenna is controlled by parameters such as plasma density, tube shape, and current distribution [3]. It has been reported that the performance of plasma antenna and metal antenna are similar in terms of their RF characteristic [5] - [6], and better in terms of robustness to thermal noise [7]

Several techniques for producing plasma were introduced. Plasma can be produced by electron impact ionization, photo-ionization, or simply heating the gas inside the tube. For plasma commercialization, mixture of mercury and argon are commonly used for fluorescent tube. Through heating process, the ability of vapour mercury to excite argon will produce ionized plasma. Gases are commonly used in plasma because of their large ionization potential which reflects the stability of electron configuration [8]. Nevertheless, variations of physical characteristics of different inert gases will result in different selection of parameters to construct the plasma antenna. Initial works to investigate the effects of different type of gases to the antenna radiation pattern and efficiency were reported in [8] - [9]. Furthermore, several methods to charge the gases into plasma state were proposed for plasma antenna construction in [10] - [11]. Among them, RF charging method is being given a lot of attention since it does not require as high peak power as the DC charging method, and having a simple charging circuit. For instance, many works have demonstrated working examples using a combination of an RF source and energy into the plasma tube, as reported in [11]. 
In this paper, the plasma antenna performance was investigated while considering the usage of different noble gas as the plasma medium, which will be charge using an RF charging with a capacitive coupling method. The study focused on the design of the coupling sleeve used, particularly by investigating the effects of number of turns of the coupling sleeve on the antenna performance. Similarly as in [9], 3 types of plasma antenna with different gases were used for comparison, namely argon, nitrogen and fluorescent (10\% mercury, $90 \%$ argon). The characteristic of the proposed plasma antennas were analyzed by CST Microwave Studio.

The rest of the paper is conducted as follows: Section II describes and explains the antenna design, the respective results and discussions, and finally conclusions and future works are summarized in Section III.

\section{Antenna Design And Simulated Result}

Monopole plasma antennas based on an RF charging were designed using CST Microwave Studio. The design of plasma antennas includes 2 different discharge tubes with length $130 \mathrm{~mm}$ and $10 \mathrm{~mm}$, and each discharge tube contains argon and nitrogen gases respectively. Figure A shows structure of proposed plasma antenna for discharge tubes argon and nitrogen. The characteristics of monopole plasma antenna for discharge tubes are compared with a commercially available fluorescent tube to analyze performance of each plasma antenna. The structure of discharge tubes is shown in Fig. 1. Each antenna is feed by SMA connector that located ends of coupling sleeve. The impedance of feeding coaxial transmission line is $50 \Omega$.

The coupling sleeve is positioned in the middle of the tubes to obtain the maximum plasma length of plasma column. The coil acts as inductance that causes an electromotive force to be generated by a changed in the flowing current. Antenna coil is needed to produce a magnetic field to ionize the plasma tube. The coil magnetic field is directly proportional to the number of turns and to the coil current due to the inductance formula.

$$
\begin{aligned}
& L=\frac{N^{2} \mu A}{l} \\
& \varepsilon=\frac{-N d \emptyset_{B}}{d t} \\
& \int d \emptyset_{B}=\int \vec{B} \cdot d \vec{A}
\end{aligned}
$$

Where $\mathrm{L}$ is the inductance of the coil in Henrys, $\mathrm{N}$ is the number of turns of coil, $\mathrm{A}$ is the area of the coil in square meters, 1 is the average length of the coil in meter, $\mu$ is the permeability of the core material, $\varepsilon$ is electromotive force in volts and $\emptyset_{B}$ is magnetic flux in Webers. According to equation (1), (2) and (3), the number of turns will have a direct effect on coil resistance. A greater number of turns of coil results in greater inductance and greater amount of magnetic field force.

Parameter structure of plasma antenna is shown in Table 1.

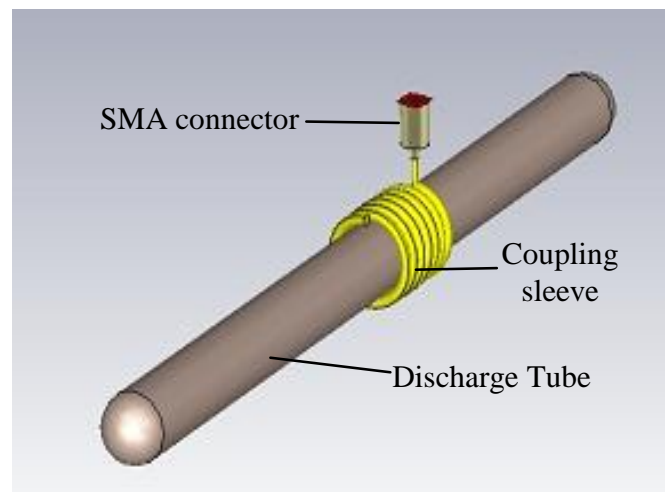

(a) Discharge tubes structure 


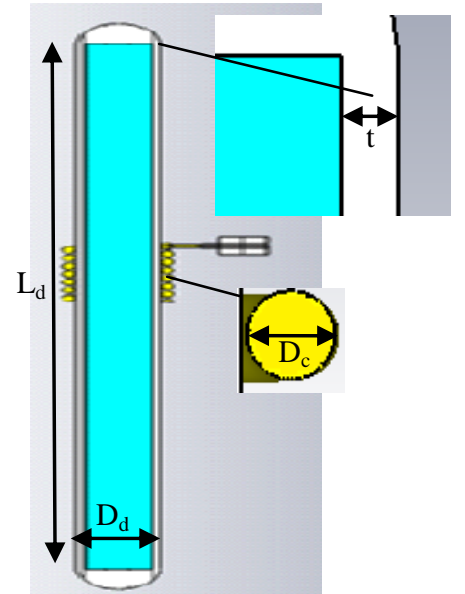

(b) Cross sectional of discharge tubes structure

Fig. 1. The structure of discharge tubes

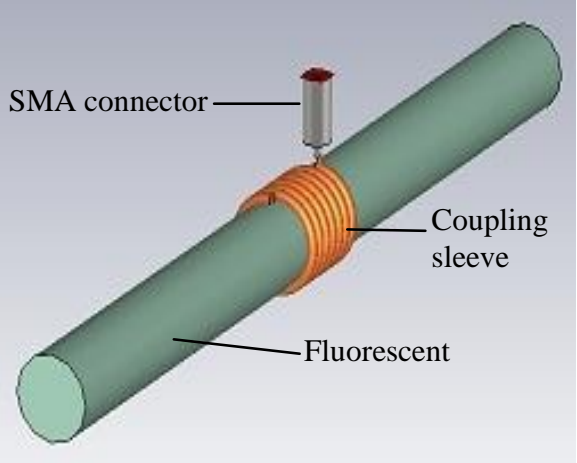

(a) Fluorescent tube structure

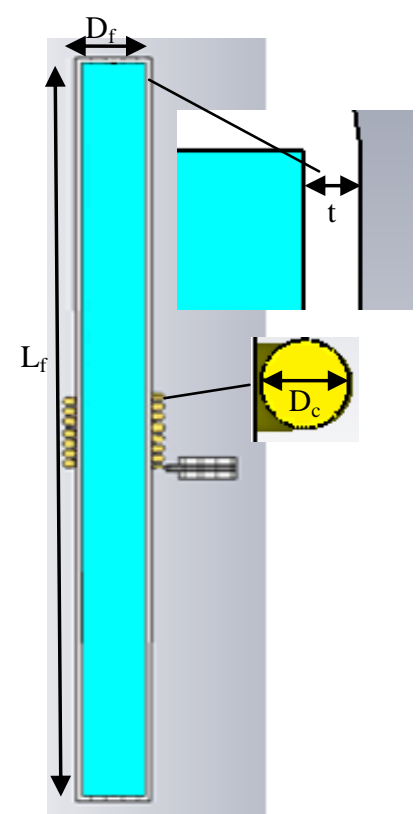

(b) Cross sectional of fluorescent tube structure

Fig. 2. The structure of fluorescent tube 
Table 1: Parameter of plasma antenna

\begin{tabular}{|l|c|}
\hline \multicolumn{1}{|c|}{ Parameter } & Value (mm) \\
\hline Diameter of coil, $\mathrm{D}_{\mathrm{c}}$ & 1.6 \\
Diameter of discharge tube, $\mathrm{D}_{\mathrm{d}}$ & 10.0 \\
Diameter of fluorescent tube, $\mathrm{D}_{\mathrm{f}}$ & 12.0 \\
Length of discharge tube, $\mathrm{L}_{\mathrm{d}}$ & 130.0 \\
Length of fluorescent tube, $\mathrm{L}_{\mathrm{f}}$ & 145.0 \\
Thickness of glass tube, $\mathrm{t}$ & 1.0 \\
\hline
\end{tabular}

\subsection{Effects of different pressure}

Monopole argon plasma antenna pressure was varied from 0.5 Torr, 1 Torr, 5 Torr to 10 Torr, in order to analyze the effects of different pressure on the antenna performance. Previous study [11] stated that, 4 no. of turns for coupling sleeve is optimum length of plasma column. This analysis was used 4 turns no. of coupling sleeve to measure performance of argon plasma antenna with different pressure. It is observed that the resonant frequency is shifted to higher frequency as shown in figure 3. Each pressure of argon plasma antenna marked slightly different return loss at different frequency, where $-17.26 \mathrm{~dB}$ at $3.58 \mathrm{GHz}$ for $0.5 \mathrm{Torr},-25.22 \mathrm{~dB}$ at 3.59 $\mathrm{GHz}$ for 1 Torr, $-26.48 \mathrm{~dB}$ at $3.66 \mathrm{GHz}$ for 5 Torr and $-27.50 \mathrm{~dB}$ at $4.44 \mathrm{GHz}$ for 10 Torr.

The corresponding performance of argon plasma antenna in Table 2 shows that different pressure gave different performance in terms return loss and gain. It was found that argon plasma antenna gave highest gain at pressure 5 Torr with $3.20 \mathrm{~dB}$ follow by 1 Torr, 10 Torr and 0.5 Torr with $2.79 \mathrm{dBm}, 2.70 \mathrm{dBm}$ and $1.63 \mathrm{dBm}$ respectively.

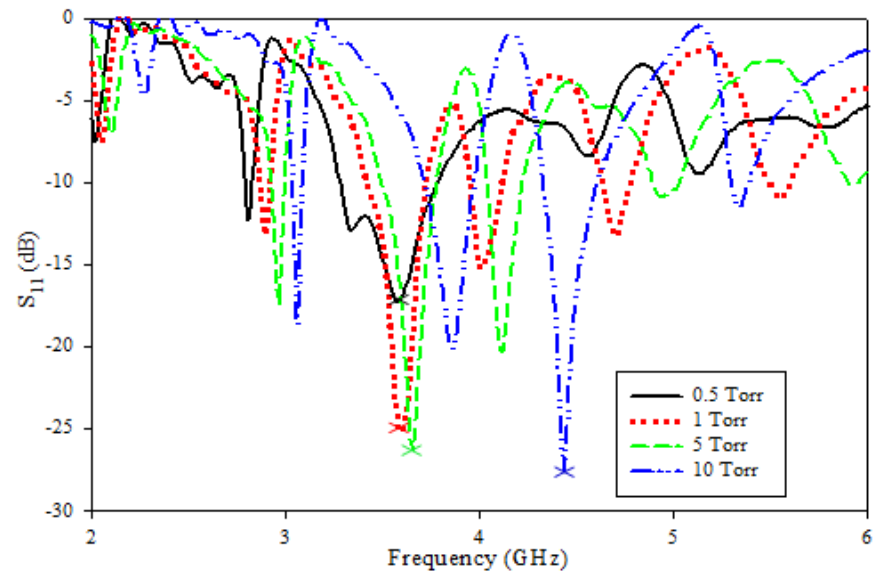

Fig. 3. Performances return loss for argon plasma antenna with different pressure.

Table 2: Performance of argon plasma antenna with different pressure

\begin{tabular}{|c|c|c|c|}
\hline $\begin{array}{c}\text { Pressure } \\
\text { (Torr) }\end{array}$ & $\begin{array}{c}\text { Frequency } \\
(\mathbf{G H z})\end{array}$ & $\mathbf{S}_{\mathbf{1 1}}(\mathbf{d B})$ & Gain $(\mathbf{d B m})$ \\
\hline 0.5 & 3.58 & -17.26 & 1.63 \\
1 & 3.59 & -25.22 & 2.79 \\
5 & 3.66 & -26.48 & 3.20 \\
10 & 4.44 & -27.50 & 2.70 \\
\hline
\end{tabular}

\subsection{Effects of different gases}

Analysis of effects of different gases involves 3 of plasma antenna which are argon, nitrogen and fluorescent. From previous analysis, argon plasma antenna gave highest gain at pressure 5 Torr. Because of fluorescent plasma antenna is used as benchmark for this analysis, the availability pressure for fluorescent only at 10 Torr. Hence, all the gases were used a same pressure and no. of turns of coupling sleeve, 10 Torr and 4 turns.

Fig. 4 represents the comparison of plasma antenna with different gases. Similar with the previous case, the results showed that different gases for the same pressure gave different performance in terms of return loss and gain.

Table 3 shows the performance of different gases of plasma antenna with same pressure. At pressure 10 Torr, nitrogen gave highest gain for plasma antenna, $3.74 \mathrm{~dB}$ at $4.19 \mathrm{GHz}$ with return loss, $-30.41 \mathrm{~dB}$ follow by 
fluorescent $3.58 \mathrm{dBm}$ at $4.05 \mathrm{GHz}$ with return loss, $-22.94 \mathrm{~dB}$ and argon $2.70 \mathrm{dBm}$ at $4.44 \mathrm{GHz}$ with return loss $27.50 \mathrm{~dB}$.

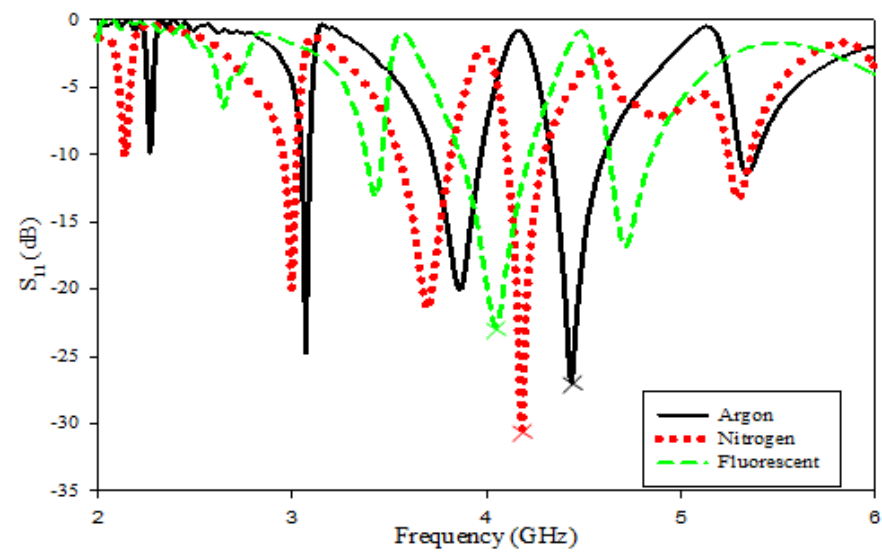

Fig. 4. Performances return loss for different gases of plasma antenna with fixed pressure of 10 Torr.

Table 3: Performance of different gas of plasma antenna with fixed pressure of 10 Torr

\begin{tabular}{|c|c|c|c|}
\hline Type of gases & $\begin{array}{c}\text { Frequency } \\
(\mathbf{G H z})\end{array}$ & $\mathbf{S}_{\mathbf{1 1}}(\mathbf{d B})$ & $\begin{array}{c}\text { Gain } \\
(\mathbf{d B m})\end{array}$ \\
\hline Argon & 4.44 & -27.50 & 2.70 \\
Nitrogen & 4.19 & -30.42 & 3.74 \\
Fluorescent & 4.05 & -22.94 & 3.58 \\
\hline
\end{tabular}

\subsection{Effects of varying no. of turns}

The simulation of plasma antenna includes 3 different gases which are argon, nitrogen and fluorescent with pressure 10 Torr. Number of turns of the coupling sleeve for each tube is varied from 2 turns until 7 turns to measure the performance of plasma antenna.

\subsubsection{Argon}

Fig.4 shows performances return loss for argon plasma antenna with different no. of turns of coupling sleeve. It is observed that each turns of coupling sleeve resulted different of resonant frequency with 2 turns have highest return loss, $-30.230 \mathrm{~dB}$ at $4.19 \mathrm{GHz}$. Table 3 represents performance of argon plasma antenna with different no. of turns of coupling sleeve. The highest gain for argon plasma antenna is 6 turns of coupling sleeve at $3.449 \mathrm{~dB}$.

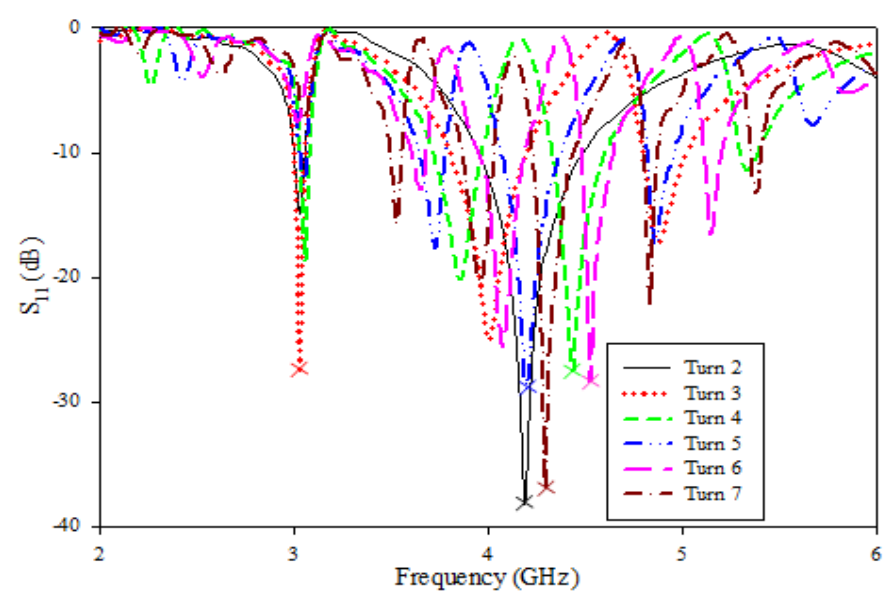

Fig. 4. Performances return loss for argon plasma antenna with different no. of turns of coupling sleeve. 
Table 3: Performance of argon plasma antenna with different no. of turns of coupling sleeve

\begin{tabular}{|c|c|c|c|}
\hline \multirow{2}{*}{$\begin{array}{c}\text { NO. OF TURNS } \\
\text { OF COUPLING } \\
\text { SLEEVE }\end{array}$} & \multicolumn{3}{|c|}{ CHARACTERISTICS } \\
\cline { 2 - 4 } & $\begin{array}{c}\text { Resonant } \\
\text { Frequency, } \\
\text { (GHz) }\end{array}$ & $\mathbf{S}_{\mathbf{1 1}}$ (dB) & $\begin{array}{c}\text { Gain } \\
\text { (dB) }\end{array}$ \\
\hline 2 & 4.19 & -38.230 & 2.22 \\
3 & 4.01 & -29.076 & 2.30 \\
4 & 4.44 & -27.497 & 2.70 \\
5 & 4.20 & -29.076 & 2.63 \\
6 & 4.53 & -28.350 & 3.45 \\
7 & 4.30 & -37.049 & 2.99 \\
\hline
\end{tabular}

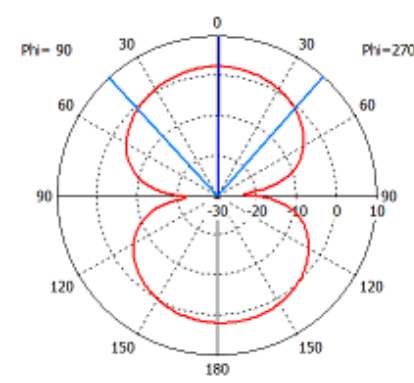

(a) 2 turns at $4.19 \mathrm{GHz}$

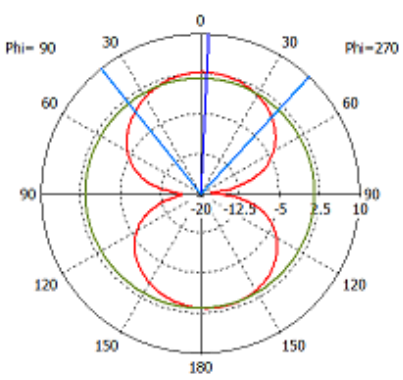

(c) 4 turns at $4.44 \mathrm{GHz}$

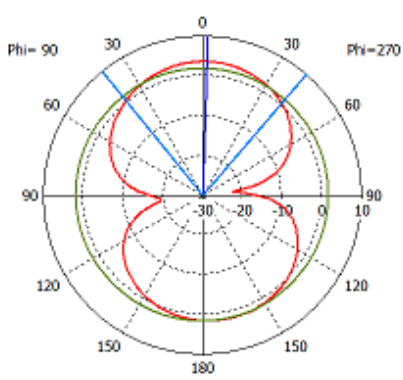

(e) 6 turns at $4.53 \mathrm{GHz}$

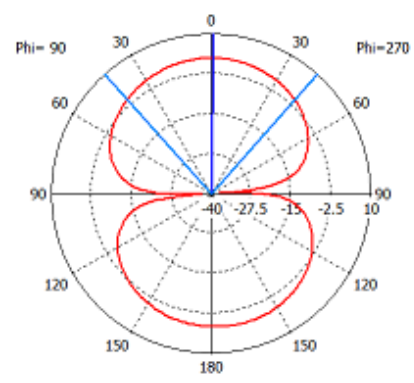

(b) 3 turns at $4.01 \mathrm{GHz}$

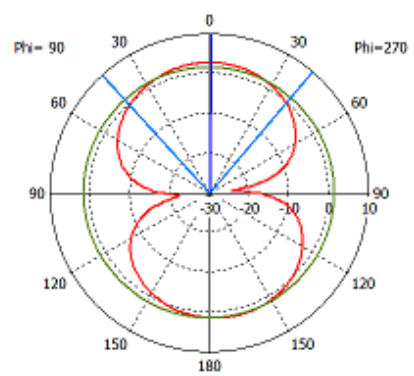

(d) 5 turns at $4.20 \mathrm{GHz}$

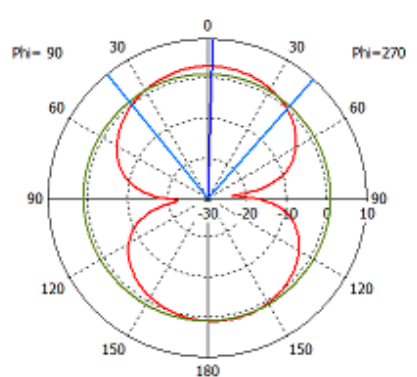

(f) 7 turns at $4.30 \mathrm{GHz}$

Fig. 5. Radiation pattern E-fields for argon plasma antenna with different no. of turns of coupling sleeve.

Fig. 5 shows radiation pattern E-plane for argon plasma antenna with different no. of turns of coupling sleeve due to optimum frequency. The E-plane radiation patterns are stably omni directional.

\subsubsection{Nitrogen}

Fig.6 shows performances return loss for nitrogen plasma antenna with different no. of turns of coupling sleeve. Similar with previous case, it was observed that each turns of coupling sleeve resulted different of resonant frequency with 4 turns have highest return loss, $-30.42 \mathrm{~dB}$ at $4.19 \mathrm{GHz}$. Table 4 represents performance of argon plasma antenna with different no. of turns of coupling sleeve. The highest gain for nitrogen plasma antenna is 6 turns of coupling sleeve at $3.269 \mathrm{~dB}$. 


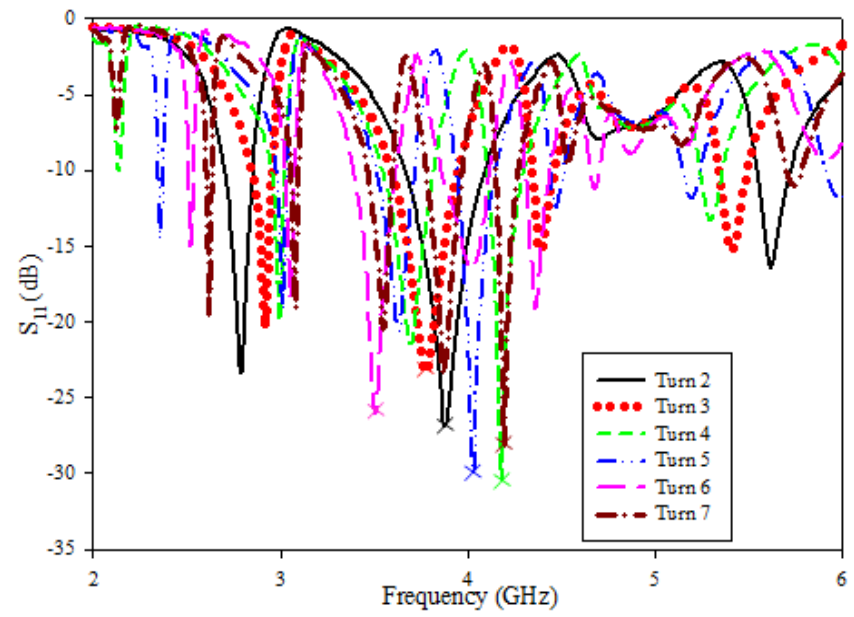

Fig. 6. Performances return loss for nitrogen plasma antenna with different no. of turns of coupling sleeve.

Table 4: Performances of nitrogen plasma antenna with different no. of turns of coupling sleeve

\begin{tabular}{|c|c|c|c|}
\hline \multirow{2}{*}{$\begin{array}{c}\text { NO. OF TURNS } \\
\text { OF COUPLING } \\
\text { SLEEVE }\end{array}$} & $\begin{array}{c}\text { CHARACTERISTICS } \\
\text { Frequency, } \\
\text { (GHz) }\end{array}$ & $\mathbf{S}_{\mathbf{1 1}}$ (dB) & $\begin{array}{c}\text { Gain } \\
\text { (dB) }\end{array}$ \\
\hline 2 & 3.88 & -26.77 & 2.14 \\
3 & 3.78 & -23.07 & 2.22 \\
4 & 4.19 & -30.42 & 2.77 \\
5 & 4.03 & -30.00 & 2.66 \\
6 & 3.51 & -25.94 & 3.27 \\
7 & 4.19 & -27.91 & 3.03 \\
\hline
\end{tabular}

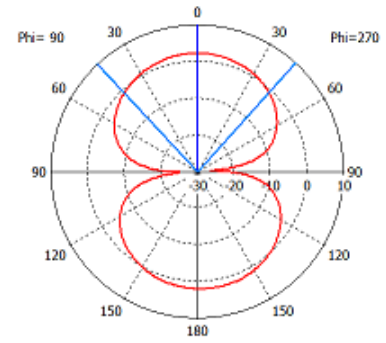

(a) 2 turns at $3.88 \mathrm{GHz}$

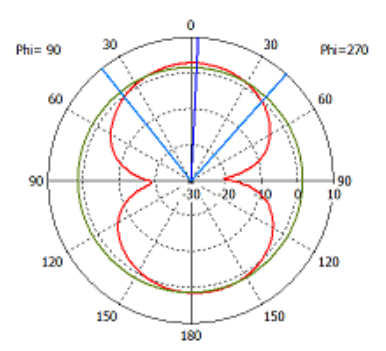

(c) 4 turns at $4.19 \mathrm{GHz}$

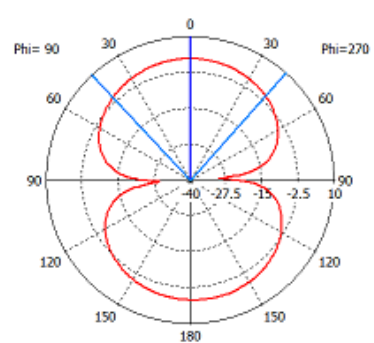

(b) 3 turns at $3.78 \mathrm{GHz}$

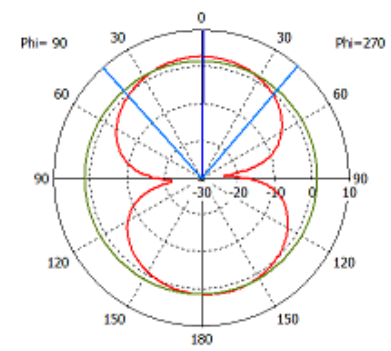

(d) 5 turns at $4.03 \mathrm{GHz}$ 


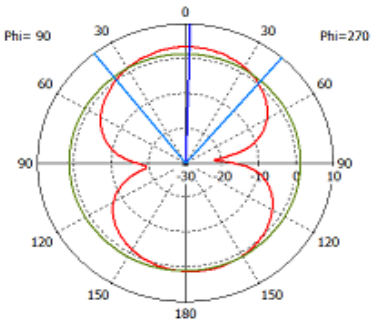

(e) 6 turns at $3.51 \mathrm{GHz}$

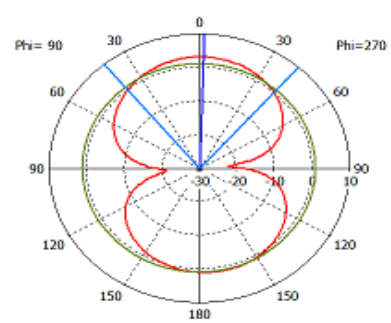

(f) 7 turns at $4.19 \mathrm{GHz}$

Fig. 7. Radiation pattern E-fields for nitrogen plasma antenna with different no. of turns of coupling sleeve.

Fig. 7 shows radiation pattern E-plane for argon plasma antenna with different no. of turns of coupling sleeve due to optimum frequency. The E-plane radiation patterns are stably omni directional.

\subsubsection{Fluorescent}

Fig.8 shows performances return loss for fluorescent plasma antenna with different no. of turns of coupling sleeve. It was found that each turns of coupling sleeve resulted different of resonant frequency with 5 turns have highest return loss, $-45.69 \mathrm{~dB}$ at $4.33 \mathrm{GHz}$. Table 5 represents performance of argon plasma antenna with different no. of turns of coupling sleeve. The highest gain for argon plasma antenna is 7 turns of coupling sleeve at $3.76 \mathrm{~dB}$.

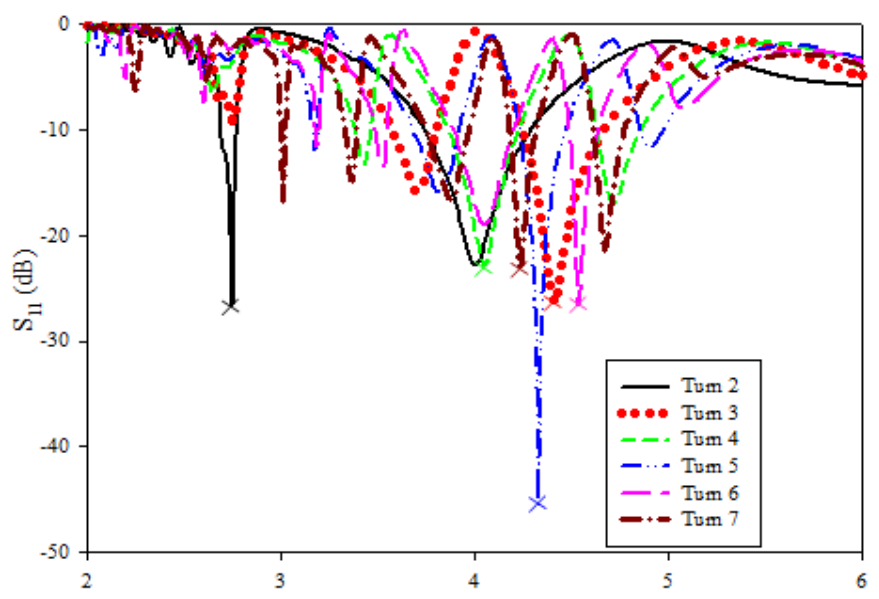

Fig. 8. Performances return loss for fluorescent plasma antenna with different no. of turns of coupling sleeve.

Table 5: Performances of fluorescent plasma antenna with different no. of turns of coupling sleeve

\begin{tabular}{|c|c|c|c|}
\hline \multirow{2}{*}{$\begin{array}{c}\text { NO. OF TURNS } \\
\text { COUPLING }\end{array}$} & \multicolumn{3}{|c|}{ CHARACTERISTICS } \\
\cline { 2 - 4 } & $\begin{array}{c}\text { Resonant } \\
\text { Frequency, } \\
(\mathbf{G H z})\end{array}$ & $\mathbf{S}_{\mathbf{1 1}}$ (dB) & $\begin{array}{c}\text { Gain } \\
\text { (dB) }\end{array}$ \\
\hline 2 & 2.75 & -26.64 & 2.38 \\
3 & 4.40 & -26.34 & 2.66 \\
4 & 4.05 & -23.21 & 3.58 \\
5 & 4.33 & -45.69 & 2.64 \\
6 & 4.53 & -26.64 & 3.15 \\
7 & 4.23 & -23.37 & 3.76 \\
\hline
\end{tabular}

Fig. 9 shows radiation pattern E-plane for argon plasma antenna with different no. of turns of coupling sleeve due to optimum frequency. The E-plane radiation patterns are stably omni directional. The radiation pattern of plasma antenna display almost identical characteristics to the radiation pattern of conventional monopole antenna. 


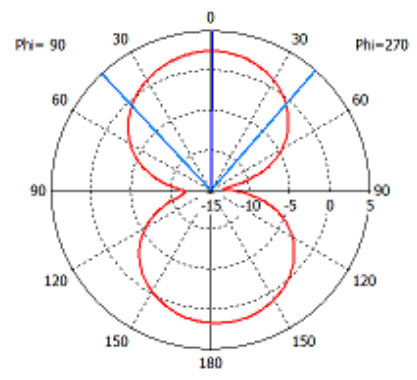

(a) 2 turns at $2.75 \mathrm{GHz}$

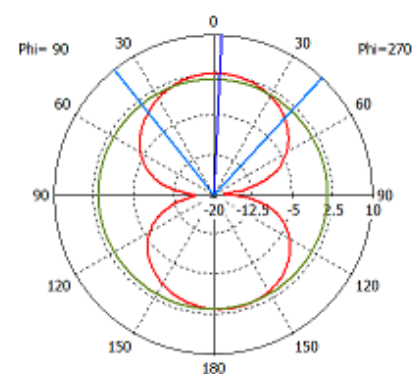

(c) 4 turns at $4.05 \mathrm{GHz}$

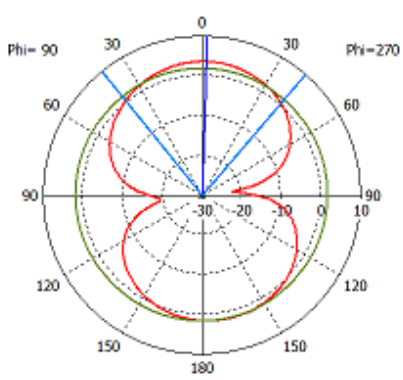

(e) 6 turns at $4.53 \mathrm{GHz}$

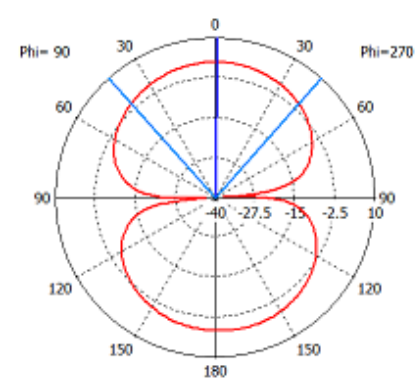

(b) 3 turns at $4.40 \mathrm{GHz}$

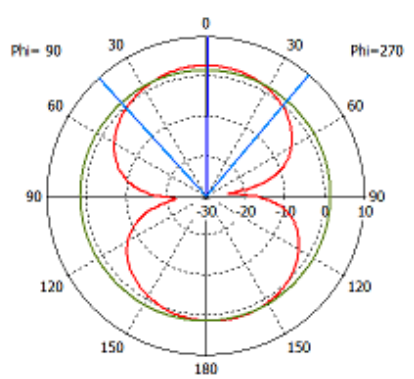

(d) 5 turns at $4.33 \mathrm{GHz}$

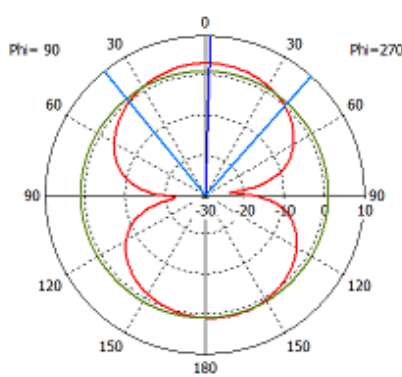

(f) 7 turns at $4.23 \mathrm{GHz}$

Fig. 9. Radiation pattern E-fields for argon plasma antenna with different no. of turns of coupling sleeve.

From the results, different gas with different pressure has different performance due to no. of coupling sleeve. According to the theory of electromagnetic inductance, more turns of the coil will generate a greater amount of magnetic field force and decreasing amount of coil current. From equation (3), it was known that permeability affects plasma density and plasma volume produced, which is when the permeability is unstable, the inductance will also be unstable as the current through the coil. In fact, plasma density and plasma volume produced were influenced the conductivity distribution of the plasma column that generated from the coil [11]. Hence, the conductivity distribution is affecting the optimum signal power due to saturated of plasma conductivity.

Meanwhile, the fluctuation of return loss due to increasing of number of turns of coupling sleeve were affected by cancelation of current due to mender line technique. By meandering line the elements the capacitance per unit length and inductance per unit length is increased. The wave velocity propagating in the mender line element were reduce, which effectively shortens the overall physical length [12].

\section{Conclusion}

The simulated performances of monopole plasma antenna with gases, pressure and number of coupling sleeve were presented. It was found that different gases of plasma antenna resulted in different of resonant frequency. Hence, plasma antenna can be use widely by consideration of the application. The capability of a plasma antenna to operate as transceiver in the particular frequency band was verified through simulation. The radiation patterns were comparable to the conventional metals antennas and the number of turns (coupling 
design) did not have significant impact on the radiation pattern. However, careful parameterization must be done to achieve a good return loss performance.

\section{Acknowledgments}

The authors would like to convey the deepest gratitude to Microwave Technology Centre (MTC), Universiti Teknologi Mara (UiTM) and Department of Physical Science, Universiti Malaysia Terengganu (UMT) for support and guidance. This research is financed by Ministry of High Education (MOHE) under grant 100-RMI / SF 16/ 6/ 2 (14/2013).

\section{References}

[1] A. Zhu, Z. Chen, J. Lv, "Reconfigurable Characteristics of the Monopole Plasma Antenna and Its Array Driven by Surface Wave", WSEAS Transactions on Communication, Issue 4, Volume 12, April 2013.

[2] J. P. Rayner, A. P. Whichello, A. D. Cheerham, "Physical characteristics of plasma antennas", IEEE Transaction on Plasma Science, vol. 32, no. 1, Feb 2004

[3] A Bogaerts, E Neyts, R Gijbels, J. V. D Muller, Gas discharge plasmas and their applications, Tata Mc-Hill, New Delhi, 2002, pp. $1-25$.

[4] N N Greenwood, A Earnshaw, Che mistry of the Elements, 2nd Edition, Butterworth-Heinemann, 1997.

[5] M. Chung, W.S. Chen, Y. H. Yu, Z.Y. Liou, "Properties of DC biased Plasma Antenna", International Conference on Microwave and Milimeter Wave Technology, Nanjing, June 2008.

[6] D. C. Jenn, Plasma Antenna: Survey of Techniques and the Current State of the Art, San Diego, CA., Sept 2003.

[7] T. Anderson, Plasma Antennas, Artech House, Massachuasetts, 2011.

[8] M. Sabouhi, B. Shokri, E. Mehrshahi, "Investigation of effects of various types of gases on radiation pattern in plasma antenna", International Conference on Plasma Science 2009, pp.1, June 2009.

[9] N. A. Halili, M. T. Ali, H. M. Zali, H. Ja'afar, I. Pasya “ A Study on Plasma Antenna Characteristics with Different Gases”, 1st IEEE International Symposium on Telecomunication Technologies 2012, pp56-59, Nov 2012.

[10] R Kumar, Plasma Antenna: Experimental Studies on Plasma Antenna, LAP Lambert Academic Publishing, 2011.

[11] N. D. Ahmad, A Kondo, H Motomura and M Jinno," Mercury-free electrodeless discharge lamp: effect of xenon pressure and plasma parameters on luminance", Journal of Physics D: Applied Physics, vol42, Issue 9, pp. 095202, May 2009.

[12] D.K.C Chew, S.R. Saunders, "Meander Line Technique for Size Reduction of Quadrifilar Helix Antenna", Antennas Wireless Propagation Letters, IEEE, vol 1, Issue 1, pp. 109-111, 2002 